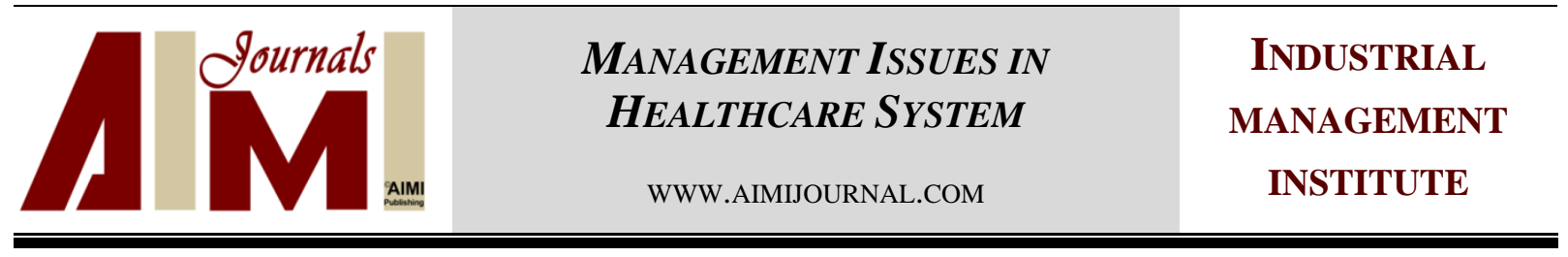

\title{
Assessing Organizational Readiness for the Improvement and Change Initiatives in Public Hospitals
}

\author{
Mohamad Alwheeb ${ }^{1}$, David M Rea ${ }^{2}$ \\ ${ }^{1}$ Ph.D. Student at Swansea University and Lecturer of Human Resources Management, College of Business \\ Administration, Majmaah University, 11952, Saudi Arabia \\ ${ }^{2}$ Associate Professor and Head of Public Health, Policy, and Social Sciences, College of Human and Health \\ Sciences, Swansea University, Singleton Park, Swansea, SA2 8PP, UK
}

Keywords:

Organizational

Readiness, Individual

Readiness, Improvement and Change Initiatives,

Justice, Equality,

Cooperation, Attitude, Behaviour

Correspondence:

M.alwheeb@mu.edu.sa

\section{ABstract}

\begin{abstract}
Despite the significant amount of research completed on the best method to manage the improvement and change activities, a high volume of research work discusses the need to evaluate the readiness aspect as an important point prior to any further act for applying new changes. This paper focuses on increasing the readiness of public hospitals in Saudi Arabia by analysing the interrelationships between organizational readiness and its impact on individual preparedness based on a mixed method approach to identify deficiencies in order to assess the potential for improvement opportunities. The research findings show that defect in organisational readiness can definitely cause significant issues for individuals' readiness, which may result in a problem for institutions and their improvement initiatives, and this may hinder the success of any change activity. Based on the findings of this study, we recommend practices that could assist in overcoming these challenges. Generally, our results focus attention on individual's attitude and willingness to change and this is argued to be a crucial factor that can lead to a success or failure of any improvement activity.
\end{abstract}

(C)AIMI Journals

\section{Introduction}

The desire for organizational change has increased exponentially, as no organization can avoid change. However, knowing of the necessity for change is one thing, preparing for it is something else. It is easy to initiate change, but the process would be fraught with risks of failure and employee resistance if the organization is not ready for it. Despite the importance of change to organizations nowadays, scholars are still divergent in determining which aspects must be adopted to prepare an organization to move forward with changes. Beer and Nohria, 
(2000) and Kotter, (1996) emphasized that almost 70\% of change movements fail and this situation has not improved (Jacobs, van Witteloostuijn, \& Christe-Zeyse, 2013; Muehlfeld, Rao Sahib, \& Van Witteloostuijn, 2012; Shah, Irani, \& Sharif, 2017). This high failure rate of change initiatives has instigated an investigation into the causes of this lack of success, which also seeks to identify factors that contribute to proper achievement of the initiatives' aims. Despite there being many frameworks presented in existing literature, there remains a lack of a valid model that organizations undergoing change can count on (Rafferty, Jimmieson, \& Armenakis, 2013). Nevertheless, most studies on organizational change have paid more attention to the antonym of change readiness, resistance to change (Holt, Armenakis, Field, \& Harris, 2007; Kotter, 1996). In this paper, the phenomenon of organizational readiness will be defined conceptually and readiness for improvement and change will be measured empirically in two levels of readiness, namely the individual and the organizational readiness level. Individual readiness focuses on employees' skills and knowledge, in addition to their perception and attitudes toward change initiatives (Armenakis, Harris, \& Mossholder, 1993). Organization readiness is identified by the evaluation of the organization structure, policy, culture, and leadership style (Rafferty et al., 2013; Vakola, 2013). By determining the meaning of organizational readiness and conducting an empirical study on the hospitals of Saudi Arabia, this study aims to identify deficiencies in improvement programs and present recommendations for actions that will rectify these issues.

\section{The Literature Review}

Organizations should always be ready to change and adapt to social and cultural needs, market developments, financial issues, and technological requirements. This can be applied to all type of organizations regardless of their size and nature, since when the organization is ready for any action such as improving the productivity or patient satisfaction, it will be able to improve its position, as the lack of readiness may raise the level of change failure. Armenakis et al. (1993) defined organizational change readiness as the attitudes and intentions toward organizational change and the capacity to apply the needed changes.

It can be said that change readiness as a concept represents an organization's willingness and preparedness to adapt to a situation, whether planned or unplanned. Change readiness as a concept takes its origin from Lewin's (1952) model, in which he described the unfreezing phase that prepares an organization for change (Holt \& Vardaman, 2013). Therefore, besides the importance of knowing when an organization is willing to change, it is also necessary to determine the organization's capacity and readiness for change, especially in a complex work processes such as a healthcare facility (Amatayakul, 2005; Sweeney \& Whitaker, 1994).

Organizational change readiness has been reviewed in the literature and at different levels. For example, Rafferty et al. (2013) emphasized that change readiness can be seen from three aspects including individual, group, and the organization. Weiner (2009) suggested that change readiness has two different forms, namely individual and organizational readiness. Indeed, organizational change readiness has been given less attention in the empirical studies than individual readiness (Weiner, Amick, \& Lee, 2008). Self, Armenakis, and Schraeder (2007) emphasized that change readiness is impacted by three aspects including the way that the change is implemented and proceeds, its relation to the change needed, and the change content that describes the change features. Holt \& Vardman (2013) divided change readiness into 
individual issues and structural issues. Creating a clear and easily understood plan is an important factor which helps to prepare employees to adequately support the change initiatives through their willingness to be part of the change. According to Dunphy and Stace (1993), to achieve considerable change, an organization should address a number of features such as its mission, values, structures, systems, policy, and communication system. Environmental aspects also play a vital role and inspire the organizational change process (Hotek \& White, 1999; Kotter, 1996).

Likewise, having a strategic direction helps the organization to prepare to effectively implement the change (Kotnour, 2011). Organizational structure with a clear plan and operation system positively affects the change process (Hall, Rosenthal, \& Wade, 1993), as changing the structure provides employees with an indicator of real change, which helps overcome employee resistance and encourages participation in the accomplishment of change initiatives. Similarly, Kanter (1984) and Eby, Adams, Russell, and Gaby (2000) emphasized that a flexible policy and optimistic organizational climate help in inspiring organizational change readiness. In the same manner, Burke \& Litwin, (1989) suggested that leadership, structure, strategy, and culture play as triggers and enablers for change. However, in this paper, readiness will be measured inn two levels, namelyorganization readiness and individual readiness.

\section{Challenges}

As described in the literature, employee resistance to change is a common phenomenon in both corporate and government organizations (Alvesson \& Sveningsson, 2008): This can be applied to all organizations regardless of their size and nature. Indeed, change is not an easy process and it is beset with difficulties mainly in resistance expressed internally or externally and intentionally or unintentionally, as opponents may not understand the advantages that can be gained from the change (Kotter \& Schlesinger, 2008; Strebel, 1996). Failure to comply with new changes and the desire to maintain the status quo are a natural phenomenon reflecting the reactions against the change. This resistance is not always a negative action but sometimes could be a positive when the proposed change is based on illogical reasons. Kotter and Schlesinger (1979) highlighted that it is important for an organization to understand the reasons for resistance and work towards determining suitable approaches to resolving the problem.

Resistance to change is often a product of fear of the unknown, fear of failure, fear of not being able to adapt to change, or inability to develop the capacities required by the new situation (Kotter \& Schlesinger, 2008; Strebel, 1996). A lack of individual understanding could also be a reason for resistance to change, since the misperception of current status and a lack of awareness of the benefits and advantages of the new situation represents a serious impediment to change. This misperception may be a result of weakened confidence from a previous change experience that did not succeed. Applying the change may also be an obstacle due to either a lack of involvement and contribution from personnel or an absence of communication (Goodman \& Truss, 2004).

Common reasons for resistance to change are an individual's preference for the status quo or a fear that their interests will be threatened (Clegg, Kornberger, \& Pitsis, 2009; Kotter \& Schlesinger, 2008; Strebel, 1996) such as loss of influence, status, potential loss of promotion, moving away from colleagues or financial loss. There are also psychological reasons that individuals generally tend to hold on to the familiar because it makes them feel safe. However, 
another challenge to organizational change is that no one approach can suit every organization (Kotter \& Schlesinger, 2008; Michel, By, \& Burnes, 2013). There are differences in size, vision, field, type of business, type of change, and other factors.

Another common view of change is that real change immediately results in increased income and stability. Change is also met with resistance due to the inability of organization leaders to provide convincing evidence that the change will be useful for both individuals and the organization (Kotter \& Schlesinger, 2008). Choosing the wrong time to initiate the change process could also be a reason why individuals do not accept it. Dissatisfaction and resistance from organization members about the new situation may occur because the change was not their choice and, specifically, it might have been imposed on them by force by people that they do not trust (Kotter \& Schlesinger, 2008; Strebel 1996). Another common reason for resistance is that employees refuse change for fear of it causing them additional burden, or that the change will require new skills and abilities that they do not possess (Kotter \& Schlesinger, 2008). Therefore, resistance to change could be a serious reason for change failure (Anderson \&Ackerman-Anderson, 2010).

The previous review shows that change is often accompanied by resistance at some stage in the process. Therefore, it is necessary to strategize in anticipation of it. Organizations that want the best result should pave the way for the change in order to avoid difficulties which may occur due to this resistance. This can be done by paying more attention at the pre-change stages and making sure that they are ready for the new changes (Armenakis et al., 1993).

\section{Method}

The research design proposes increasing control over factors that could interfere with the desired results of the study (Burns \& Grove, 2003). Sarantakos (1998) suggested that the research objective determines the research design, therefore, there is no best research option. Some researchers prefer the quantitative method; they use, for example, a survey method to save time by using an online questionnaire and analyzing the data using statistic programs such as SPSS and Stata. Following this, others prefer the qualitative method because it provides them with access to in-depth evidence about the phenomena. In this study both methods are used to reach the aim of the study, as each approach focuses on different aspects and it is more likely to gain benefits from both approaches when using them together (Zammuto \& Krakower, 1991). The collective taking advantage of both approaches is known as the mixed-method approach (Azorin \& Cameron, 2010). However, the data analysis conducted in this study includes descriptive analysis, inferential techniques, and thematic analysis (Creswell \&Plano Clark, 2011).

Questionnaire was used to measure the employees' opinion about the organization and individual readiness to change. The instrument items were modified from the NHS Innovation and Improvement Survey in 2009 that include 22 variables related to improvement practices. The questionnaire included a demographic set of questions that build strong criteria in different characteristics to link between participants' personal and professional background and their answers to the survey items. In the second section, the participants were asked about the improvement activities to specify the degree to which they think about the items in the questionnaire by using Likert scale ranging from strongly agree (five points), Agree (four points), Neutral (three points), Disagree (two points), and Strongly Disagree (one point). This 
can help to gain reliable results on employees' opinion about the current situation of their institutions. The third section included two ranking question to rank the challenges and recommendations, and lastly the forth section covered an open-ended question that asked participants about their opinion of the best practice to have a successful improvement activity. To support the data findings, a semi-structured interview conducted with 29 top managers and supervisors who are involved in improvement programs. The interview questions in this research were formulated based on the questionnaire finding; the questions were built to remedy the issues that were not included in the questionnaire which helped gaining an in-depth information about the causes of the discussed phenomenon.

\section{Results}

The analysis was split into two sections: Section One (see Table 1) contained a descriptive analysis that included the demographic questions in addition to the employees' opinion of the readiness for change. Most of the participants were female and between 31-40 years old. In terms of educational background, employees with a Bachelor's degree comprised the majority of the participants, the highest range for experience is 0-10 years, and lastly, almost half of the employees claimed that they had not previously participated in improvement projects. The employee perceptions of the readiness to change items revealed a low approval rate that ranged from 40 to 60 percent. The findings showed a lack of support from higher authority and insufficient resources, and the employees' views also highlighted weaknesses in the evaluation of improvement projects and ineffective training programmes. Table 1 shows the demographic characteristics.

Table 1

Demographic Characteristics

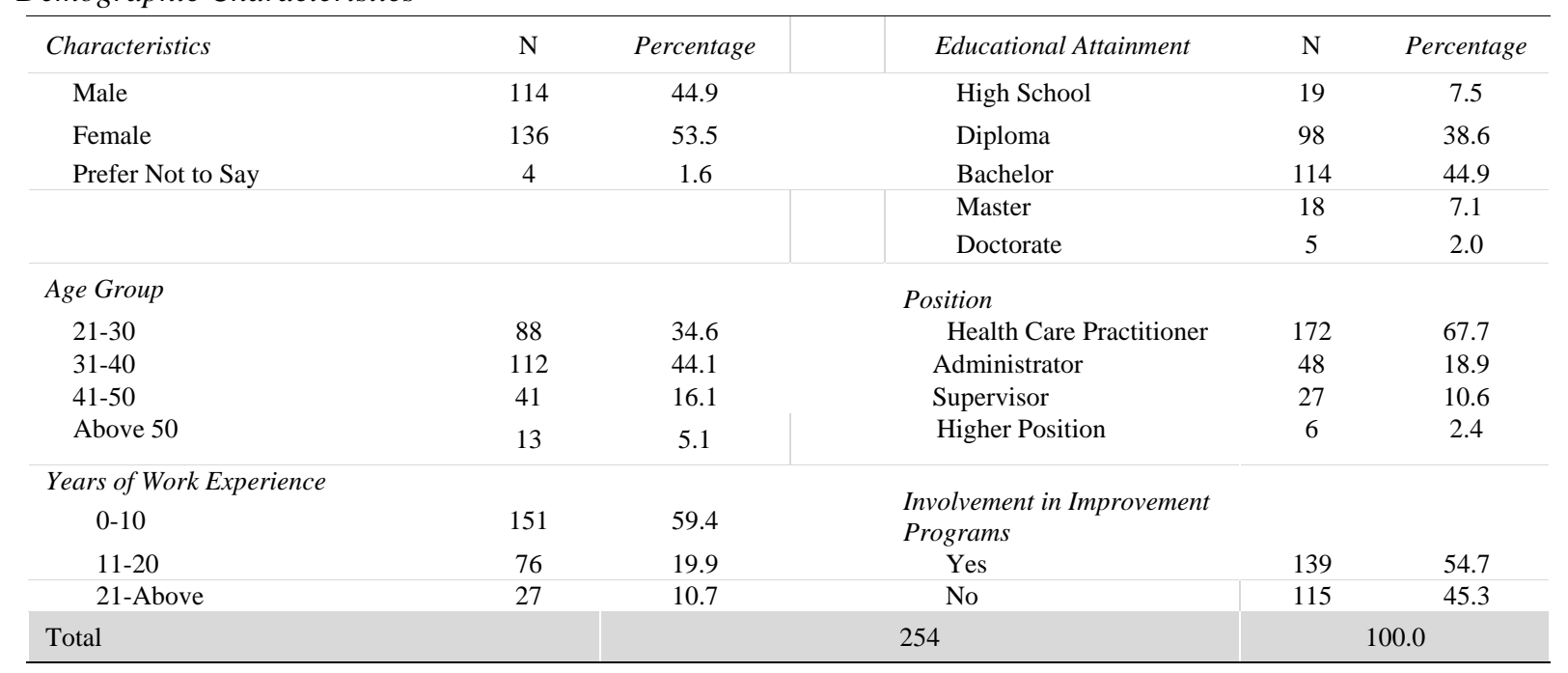

The second section presents an inferential analysis to determine the relationship amongst employees' varying perceptions of the readiness to change. To determine the differences between employee perceptions of the readiness to change and demographic questions, the study used the Mann-Whitney and Kruskal-Wallis tests. The tests revealed no significant differences between employee perceptions of organisational readiness, however, a significant difference existed between their perceptions on individual readiness variables. The findings also showed a 
significant difference in employee perceptions of individual readiness variables based on their experience and no significant difference for the organisational readiness variables. Furthermore, the findings revealed that there is no significant difference between employee perceptions based on their position, education or age. Lastly, the findings showed that there is a significant difference in the employees' perceptions of both the organization and individual readiness to change variables based on their previous participation in improvement programs.

The inferential analysis also utilizes a Spearman correlation test to determine the relationship between employees' responses and participant demographics that have a significant impact on the employees' opinions regarding the readiness to change items, in addition to the relationship between the organization readiness and individual readiness variables. The findings presented several correlations. Generally, the correlations between the readiness to change items and participant demographics are negative low significant correlations. The highest correlation is found to be between the individual readiness and the organisation readiness variables at 0.82 .

The findings in Table 2 indicates that the most significant challenge faced by hospitals in their previous improvement activities was the absence of an 'improvement culture' with 13.4 percent of the entire response and 38 participants perceiving it tended to be the number one obstacle. Moreover, 12.3 percent of the participants identified lack of staff comprehension of improvement programs as the second most significant barrier. Further, the lack of staff skills and capabilities was seen to be the third greatest challenge with 12 percent of the total response and 27 participants identified it as the greatest difficulty. Other identified obstacles to the improvement projects are the absence of 'successfully involving patients and the public' to inform improvement activities with 10.4 percent and leadership of improvement with 9.8 percent.

The results showed that the best practice that participants believe could help in improvement projects is 'improving productivity through quality improvement' with 19.7 percent of responses, and 38 employees indicated it as the number one action for the improvement; following this, 43 and 34 respondents chose it as a second and a third choice, respectively. This was not surprising as the employees have been accustomed to quality assurance standards which they have been forced to apply under the instruction of the Saudi Ministry of Health. 'Whole-system approaches to improvement' comes second with 18.8 percent of the total response; moreover, 52 employees agreed that it is the best action for the improvement, and only 21 participants selected it as the next action for the improvement. Table 2 exhibits the challenges to improvement projects.

In answering the open-ended questions, the participants came up with 236 responses that support the amendment of many practices: These responses have been categorised into nine different factors. For example, one of the employees recommended having "Constant communication with employees, listening to them, and solving their work problems". This statement was categorised under the need to improve the communication system. 
Table 2

Challenges to Improvement Projects

\begin{tabular}{|c|c|c|c|c|c|}
\hline \multirow{2}{*}{$\begin{array}{l}\text { Challenges } \\
\text { Ranking }\end{array}$} & \multicolumn{5}{|c|}{ Participants’ Opinion } \\
\hline & 1 & 2 & 3 & Total Points & $\%$ \\
\hline Developing/Embedding an Improvement Culture & 38 & 17 & 11 & 159 & $13.4 \%$ \\
\hline Embedding Improvement in Commissioning Processes & 12 & 18 & 14 & 86 & $7.2 \%$ \\
\hline Ensuring that Improvements Are Sustained & 8 & 15 & 18 & 72 & $6 \%$ \\
\hline Gaining Board Level Commitment for Improvement & 15 & 5 & 21 & 76 & $6.4 \%$ \\
\hline Gaining Commitment from other Key Staff Across the Organisation & 14 & 26 & 14 & 108 & $9.1 \%$ \\
\hline Improving Staff Skills and Capability & 27 & 22 & 17 & 142 & $12 \%$ \\
\hline Improving Staff Understanding of Improvement & 19 & 32 & 25 & 146 & $12.3 \%$ \\
\hline Leadership of Improvement & 21 & 16 & 21 & 116 & $9.8 \%$ \\
\hline Maintaining Improvement Activities Whilst Reducing Costs & 3 & 7 & 15 & 38 & $3.2 \%$ \\
\hline Measuring Outcomes of Improvement & 8 & 14 & 18 & 70 & $5.9 \%$ \\
\hline Providing Evidence for the Financial Benefits of Improvement & 8 & 11 & 5 & 51 & $4.3 \%$ \\
\hline Successfully Involving Patients and the Public to Inform Improvement Activities & 25 & 15 & 19 & 124 & $10.4 \%$ \\
\hline Total & & & & 1188 & $100 \%$ \\
\hline
\end{tabular}

Analysis of the semi-structured interview data shows that there are several issues regarding the change movement. It is clear that the changes were dependant on the improvement necessities imposed by the quality assurance requirements. However, the participants indicated that they faced several obstacles which hindered the success of their change and improvement projects. These include but were not limited to lack of manpower, lack of support, lack of employee readiness, lack of communication practice, and an ineffective policy and work system.

The findings illustrated that the lack of authority constituted an obstacle to creativity and productivity, as the inability of managers to punish neglected employees may cause their performance to decline, and in turn, generate an unhealthy work culture. Also, the impact of the policy and regulation weaknesses had a negative effect on the employees' attitudes and behaviours. The results also indicated the inequality between employees caused by policy and regulations or other management practices, and an absence of justice that resulted in a change in the employees' attitudes and motives. Generally, the weaknesses of the current policies and regulations have contributed to an unhealthy organisation culture. Furthermore, the apparent imbalance in the current organisational culture and, specifically, the policy and regulations, has led to an inability to provide effective services in addition to hindering the ability to complete improvement programs.

The results of the qualitative research data also expose other problems that affect the success of the improvement and change process. These can generally be addressed through the implementation of a consistent salary system and by eliminating inequalities with foreigners, allowing a smooth transformation.

To conclude, the majority of the participants believed that there is a direct link between the current status of their organisational culture and the change process. However, taking into account both the contradictions and similarities between quantitative and qualitative results, this empirical study might help in finding recommendations that contribute to the readiness to change in Ministry of Health hospitals in Saudi Arabia. 


\section{Discussion and Conclusion}

The importance of change came from the constant need to adjust and change objectives in line with the requirements of renewal and change. This paper was carried out to determine the deficiencies and challenges to improvement programs and provide recommendations to have successful change initiatives. The findings derived from the quantitative data indicated that the most challenges faced by hospitals were due to the absence of an improvement culture, lack of staff comprehension of improvement programs, the lack of staff skills and capabilities, the absence of successfully involving patients and the public to inform improvement activities, and lastly, the absence of having leadership of improvement. Similarly, the interview participants emphasised several obstacles such as the lack of manpower, support, employee readiness, communication system, and an ineffective policy and work system that hindered the success of the improvement projects. Also, the absence of justice and inequality between employees caused by policy and regulations result in a shift in employees' attitudes and motives. Generally, the findings of the interviews highlighted a weakness in policies and regulations which led to an unhealthy organisation culture. This corresponds with the questionnaire findings.

The participants recommended several solutions such as improving productivity through quality improvement and having a whole-system approaches to improvement. They also believe training comes at the forefront of potential solutions that may help the implementation of change and improvement projects. Improving the communication system was also one of the recommendations mentioned by the participants in addition to improving leadership skills. Regarding the problem of the absence of justice, this issue can be addressed through the implementation of a consistent salary system and the elimination of inequalities with foreigners.

To conclude, most participants believed that there is a direct link between the current status of their organisational culture and the change process. However, considering both the contradictions and similarities between quantitative and qualitative results, a recommendation for further research studies is to determine which organisational culture factors most significantly affect the readiness to change.

\section{References}

Alvesson, M., \&Sveningsson, S. (2008). Changing organizational culture: Cultural change a work in progress. London, UK: Routledge.

Amatayakul, M. (2005). EHR? Assess Readiness First. Journal of the Healthcare Financial Management Association, 59(5), 112-13.

Anderson, D., \& Ackerman-Anderson, L. (2010). Beyond change management: How to achieve breakthrough results through conscious change leadership ( $2^{\text {nd }}$ ed.). San Francisco: Pfeiffer.

Armenakis, A. A., Harris, S. G., \&Mossholder, K. W. (1993). Creating readiness for organizational change. Human Relations, 46, 681-703.

Azorin, J. M., \& Cameron, R. A. The application of mixed methods in organisational research: A literature review. Electronic Journal of Business Research Methods, 8(2), 95-105.

Beer, M., \& Nohria, N. (2000). Breaking the code of change. Boston: Harvard Business School Press.

Burke, W. W. \& Litwin, G. H. (1989). A causal model of organizational change and performance. In J. W. Pfeiffer (Ed.), The 1989 Annual:Developing human resources (277-288). San Diego, CA: University Associates.

Burns, N., \& Grove, S. K. (2003). Understanding nursing research ( $3^{\text {rd }}$ ed.). Philadelphia: W. B. Saunders Company. 
Clegg, S., Kornberger, M., \&Pitsis, T. (2008). Managing and organizations: An introduction to theory and Practice. London: SAGE publications.

Creswell, J. W., \& Plano Clark, V. L. (2011). Designing and conducting mixed methods research. (2 ${ }^{\text {nd }}$ ed.). Thousand Oaks, CA: SAGE.

Dunphy, D., \& Stace, D. (1993). The strategic management of corporate change. Human Relations, 46(8), 905-920.

Eby, L. T., Adams, D., M., Russell, J. E. A., \& Gaby, S. H. (2000). Perceptions of organizational readiness for change: Factors related to employees' reactions to the implementation of team-based selling. Human Relations, 53(3), 419-442.

Goodman, J., \& Truss, C. (2004). The medium and the message: communicating effectively during a major change initiative. Journal of Change Management, 4(3), 217-228.

Hall, J., Rosenthal, J., \& Wade, J. (1993). How to make reengineering really work. Harvard Business Review, 73(6), 119-31.

Holt, D. T., Armenakis, A. A., Feild, H. S., \& Harris, S. G. (2007). Readiness for organizational change: The systematic development of a scale. Journal of Applied Behavioral Science, 43(2), 232-255.

Holt D. T., \& Vardaman J. M. (2013). Towards a comprehensive understanding of readiness for change: The case for an expanded conceptualisation. Journal of Change Management, 13(1), 9-18.

Hotek, D. R., \& White, M. R. (1999). An overview of performance technology. Journal of Technology Studies, 25(1), 4350 .

Jacobs, G., van Witteloostuijn, A., \& Christe-Zeyse, J. (2013). A theoretical framework of organizational change. Journal of Organizational Change Management, 26(5), 772-792.

Kanter, R. M. (1984). The change masters. Training \& Development Journal, 38(4), 39-43.

Lewin, K. (1952). Field theory in social science: Selected theoretical papers by Kurt Lewin. London: Tavistock.

Kotter, J. P. (1996). Leading change. Boston: Harvard Business School Press.

Kotter, J. P., \& Schlesinger, L. A. (2008). Choosing strategies for change. Harvard Business Review, 86(7/8), 130-139.

Kotter, J. P., \& Schlesinger, L. A. (1979). Choosing strategies for change. Harvard Business Review, 57, 106-114.

Kotnour, T. (2011). An emerging theory of enterprise transformations. Enterprise Transformation, 1(1), 48-70.

Michel, A., By, R. T., \& Burnes, B. (2013). The limitations of dispositional resistance in relation to organizational change. Management Decision, 51(4), 761-780.

Muehlfeld, K., Rao Sahib, P., \& Van Witteloostuijn, A. (2012). A contextual theory of organizational learning from failures and successes: A study of acquisition completion in the global newspaper industry, 1981-2008. Strategic Management Journal, 33(8), 938-964.

Rafferty, A. E., Jimmieson, N. L., \& Armenakis, A. A. (2013). Change readiness: A multilevel review. Journal of Management, 39(1), 110-135.

Sarantakos, S. (1998). Social research ( $2^{\text {nd }}$ ed.). Basingstoke: Macmillan.

Self, D. R., Armenakis, A. A., \& Schraeder, M. (2007). Organizational change content, process, and context: A simultaneous analysis of employee reactions. Journal of Change Management, 7, 211-229.

Shah, N., Irani, Z., \& Sharif, A. (2017). Big data in an HR context: Exploring organizational change readiness, employee attitudes and behaviors. Journal of Business Research, 70, 366-378.

Strebel, P. (1996). Why do employees resist change? Harvard Business Review,74, 86-92.

Sweeney, Y. T., \& Whitaker, C. (1994). Successful change: Renaissance without revolution. Semin Nurse Management, 2 , 196-202.

Vakola, M. (2013). Multilevel readiness to organizational change: A conceptual readiness to organizational change: a conceptual approach. Journal of Change Management, 13(1), 96-109.

Weiner, B. J., Amick, H., \& Lee, S. Y. D. (2008). Conceptualization and measurement of organizational readiness for change: A review of the literature in health services research and other fields. Medical Care Research \& Review, 65(4), 379-436.

Weiner, B. (2009). A theory of organizational readiness for change. Implementation Science, 4(1), 67-75.

Zammuto, R. F., \& Krakower, J. (1991). Quantitative and qualitative studies of organizational culture. In R. W. Woodman, \& W. A. Passmore (Eds.), Research in organizational change and development (pp. 83-144). Greenwich, CT: JAI Press. 